\title{
Acromegaly associated with GIST, non-small cell lung carcinoma, clear cell renal carcinoma, multiple myeloma, medulla oblongata tumour, adrenal adenoma, and follicular thyroid nodules
}

\author{
Aleksandra Jawiarczyk-Przybyłowska' ${ }^{1}$ Beata Wojtczak' ${ }^{2}$, James Whitworth ${ }^{3}$, Krzysztof Sutkowski ${ }^{2}$, \\ Martin Bidlingmaier ${ }^{4}$, Márta Korbonits ${ }^{5}$, Marek Bolanowski ${ }^{1}$ \\ ${ }^{1}$ Department of Endocrinology, Diabetes, and Isotope Therapy, Medical University Wroclaw, Poland \\ ${ }^{2}$ Department of Endocrinological Surgery, Medical University Wroclaw, Poland \\ ${ }^{3}$ Department of Medical Genetics, University of Cambridge Cancer Research UK Cambridge Centre, United Kingdom \\ ${ }^{4}$ Endocrine Laboratory, Ludwig-Maximilians-University of Munich, Germany \\ ${ }^{5}$ Centre for Endocrinology, Barts and the London School of Medicine, Queen Mary University of London, United Kingdom
}

\begin{abstract}
Acromegaly is associated with increased growth hormone $(\mathrm{GH})$ and insulin-like growth factor-I (IGF-I) secretion which may support tumour development and growth.

A 68-year-old woman was diagnosed with acromegaly due to typical clinical and hormonal characteristics. While contrast-enhanced MRI at diagnosis did not reveal a pituitary adenoma, a 5-mm lesion was identified on repeat scanning 13 months later. Abdominal and chest CT showed tumours of the stomach, right adrenal gland, and right lung. The CT also showed a hypodense lesion in the liver and heterogeneous echostructure of the thyroid gland with left lobe solid-cystic tumour. Somatostatin receptor scintigraphy revealed increased tracer accumulation in the right thyroid lobe. No tracer accumulation was noted at the location of the other tumours. The resected stomach, adrenal, chest, and thyroid lesions did not show GH secretion. The patient refused pituitary surgery, and her acromegaly is currently well-controlled with somatostatin analogue therapy. A CT scan 19 months later revealed a contrast-enhancing left kidney tumour that was a G1-grade clear cell carcinoma. Four years after the acromegaly diagnosis multiple myeloma were diagnosed with secondary renal amyloidosis. Genetic screening for a paraganglioma gene panel, AIP, MEN1, and CDKN1B mutations were negative. A next-generation cancer panel containing 94 cancer genes did not identify any possible unifying gene abnormality in her germline DNA.

Coexistence of acromegaly and numerous other tumours suggests a common aetiology of these disorders. However, no genetic abnormality could be identified with the tests that have been performed. (Endokrynol Pol 2019; 70 (2): 213-218)

Key words: patient; acromegaly; multiple tumours; genetics
\end{abstract}

\section{Introduction}

Acromegaly is a rare disease caused by hypersecretion of growth hormone $(\mathrm{GH})$ and its peripheral mediator insulin-like growth factor I (IGF-I). The most common cause is a pituitary adenoma, a monoclonal tumour, which occurs sporadically or, rarely, in a familial setting [1]. In approximately $1 \%$ of all cases the root cause is ectopic secretion of GHRH. A few cases of GH secretion by non-Hodgkin's lymphomas, and neuroendocrine tumours have been described in the literature $[2,3]$. Excess GH results in enlargement of soft tissues, hands, and feet and causes prominent forehead, jaw, and nose. Acromegaly can be a part of rare syndromes coexisting with other endocrine tumours (MEN1, MEN4, Carney complex, McCune-Albright, SDHx-related pituitary adenoma) or be present as a part of familial isolated pituitary adenoma (FIPA) syndrome. In addition to the classical signs, symptoms, and complications of acromegaly, the possibility of an increased risk of benign and malignant neoplasms has been raised [4]. The objective of our report was to study the genetic background of a patient with acromegaly accompanied by other neoplasms.

\section{Case report}

We present a female patient suffering from acromegaly and with multiple tumours (Fig. 1). Acromegaly was diagnosed at the age of 68 years based on the typical clinical picture (facial appearance, gradual increase in shoe and glove size, necessity of ring enlargement) and biochemical investigations [IGF-I $586 \mathrm{ng} / \mathrm{mL}$ (age-related normal range: 68-200), oral glucose tolerance test GH 

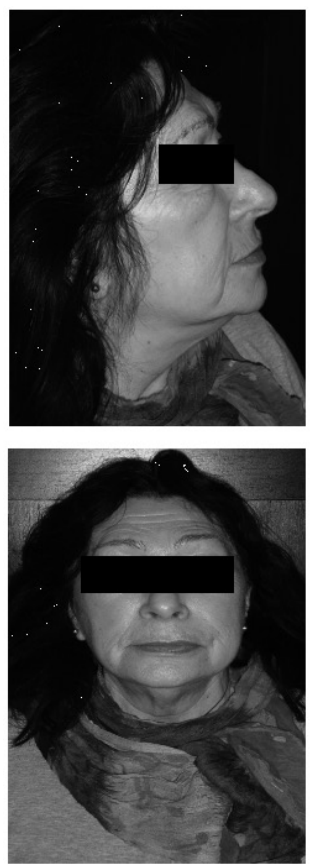

Medullata oblongata tumour

$49 \mathrm{y}$

69 y

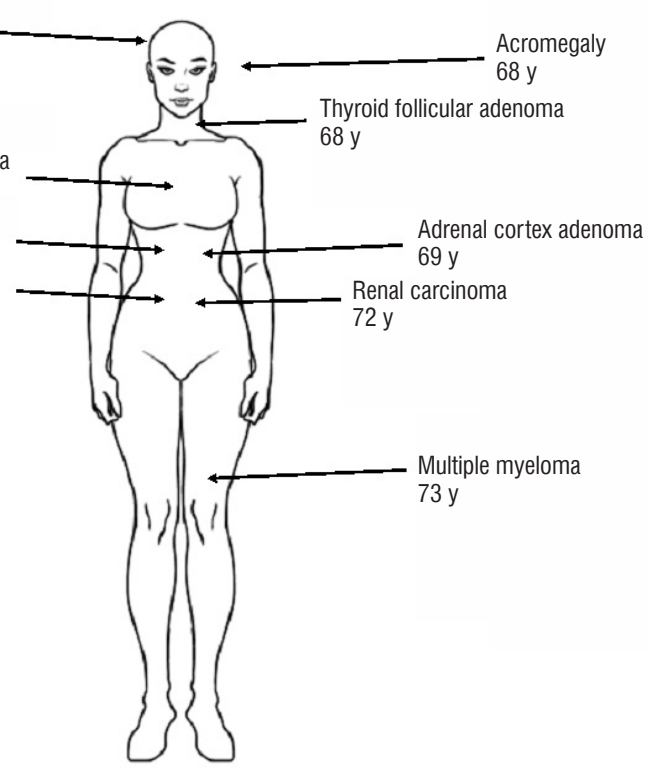

Figure 1. Patient with acromegaly and multiple neoplasms

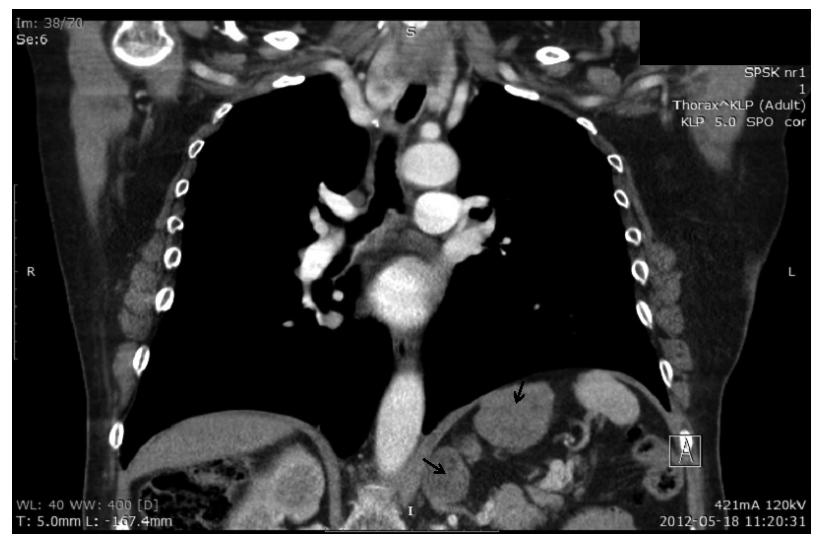

Figure 2. Stomach tumour $(5.0 \times 4.2 \times 3.97 \mathrm{~cm})$, left adrenal gland tumour $(2.5 \times 3.7 \times 3.4 \mathrm{~cm})$

nadir $1.96 \mathrm{ng} / \mathrm{mL}]$. However, contrast-enhanced MRI at diagnosis did not reveal a pituitary adenoma. The rest of the pituitary function was normal. In addition, the patient suffered from type 2 diabetes, hypertension, osteoarthritis, nephrolithiasis, gallbladder polyps, and a hepatic cyst. Her corrected serum calcium, urinary calcium, and parathormone levels were normal. There was no family history of pituitary or other endocrine or non-endocrine tumours. She was operated for a medulla oblongata tumour at the age of 49 years.

Because no tumour was shown on pituitary MRI, we started to search for an ectopic source of GHRH or GH. At first, we performed abdominal and chest CT, which revealed multiple tumours: stomach $(5.0 \times 4.2 \times 3.97 \mathrm{~cm})$, left adrenal gland $(2.5 \times 3.7 \times 3.4$

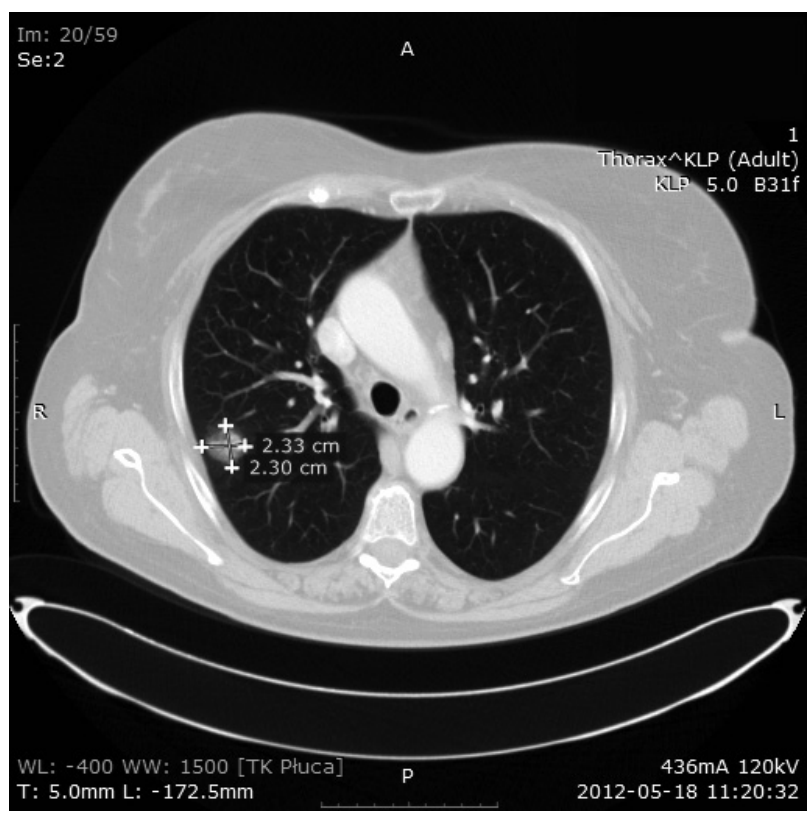

Figure 3. Right lung tumour $(2.3 \times 2.33 \times 2.21 \mathrm{~cm})$

cm) (Fig. 2), right lung $(2.3 \times 2.33 \times 2.21 \mathrm{~cm})($ Fig. 3), and a hypodense $1.6-\mathrm{cm}$ lesion in segment $\mathrm{IVb}$ of the liver. The gastric tumour was located at the border of the gastric cardia and corpus, invading the stomach wall. The solid left adrenal lesion had different contrast enhancement characteristics, suggesting that it was not a metastasis from the stomach tumour. Investigations towards hypercortisolism (dexamethasone suppression test) or a phaeochromocytoma (repeated urinary metanephrines) were negative. She had normal blood 
Table I. Histopathology results

\begin{tabular}{ll}
\hline Organ & Histology \\
\hline Stomach & Gastrointestinal stromal tumour (GIST) \\
& Vimentin, CD34, CD $117(+++)$ \\
& Ki67: $(+)<0.5 \%$ of cells \\
& Desmin, SMA (-), Mitosis 0.50 HPV \\
\hline Liver & Chronic reactive hepatitis without cirrhosis and \\
& neoplasm \\
& Masson trichrome (-), silver reticulin staining (-) \\
& Ferrum (-) \\
\hline Thyroid & Thyroid follicular adenoma, CgA (-), Calcitonin (-) \\
\hline Adrenal & Adrenal cortical adenoma \\
gland & Melan A, CD56, Calretinin (++) \\
& S-100, Inhibin (-) \\
\hline Lung & Adenocarcinoma, non-microcellular carcinoma (G2) with \\
& no lymphatic node metastases (pT1B No Mx Ro Lo) \\
\hline Kidney & Clear cell renal cell carcinoma (CCRCC), G1 \\
& IgG (+), IgA (-), IgM (+), IgKappa (+), IgLambda (+) \\
& PAS (+), Mallory's trichrome stain (+), Congo red (+) \\
\hline
\end{tabular}

pressure. Thyroid ultrasound showed heterogeneous echostructure in general, right lobe enlargement, and a left lobe solid-cystic focus of $2.6 \mathrm{~cm}$ in diameter. Fine-needle aspiration showed Bethesda III grade cells, which were negative for chromogranin and calcitonin. Serum calcitonin level was normal $(<2 \mathrm{pg} / \mathrm{mL})$. Somatostatin receptor scintigraphy showed increased tracer accumulation in the right thyroid lobe, while no tracer accumulation was noticed in the lesions in the lung and stomach. A few months after the diagnosis of acromegaly, somatostatin analogue therapy (octreotide LAR $30 \mathrm{mg}$ monthly) was started. Partial stomach and left liver lobe resections were performed. Histopathological examination revealed a gastrointestinal stromal tumour (GIST) and chronic reactive hepatitis without cirrhosis and neoplasm (Tab. I). Thyroid surgery (three months later) and left adrenalectomy (seven months later) were performed showing thyroid follicular adenoma and an adrenal cortical adenoma (Tab. I). Three plasma samples were studied for GHRH: the first at the time of the diagnosis of acromegaly — before somatostatin analogue therapy, the second after the GIST resection while on somatostatin analogue therapy, and the third after thyroid surgery. In all three samples GHRH levels were low normal. Moreover, we did not observe an overall enlargement of pituitary gland on the pituitary MRI, typical for ectopic source of GHRH. A repeat pituitary MRI 13 months after the diagnosis of acromegaly showed a 5-mm mixed-signal anterior pituitary lesion on T2-weighted images, which was hypodense after contrast infusion, corresponding to

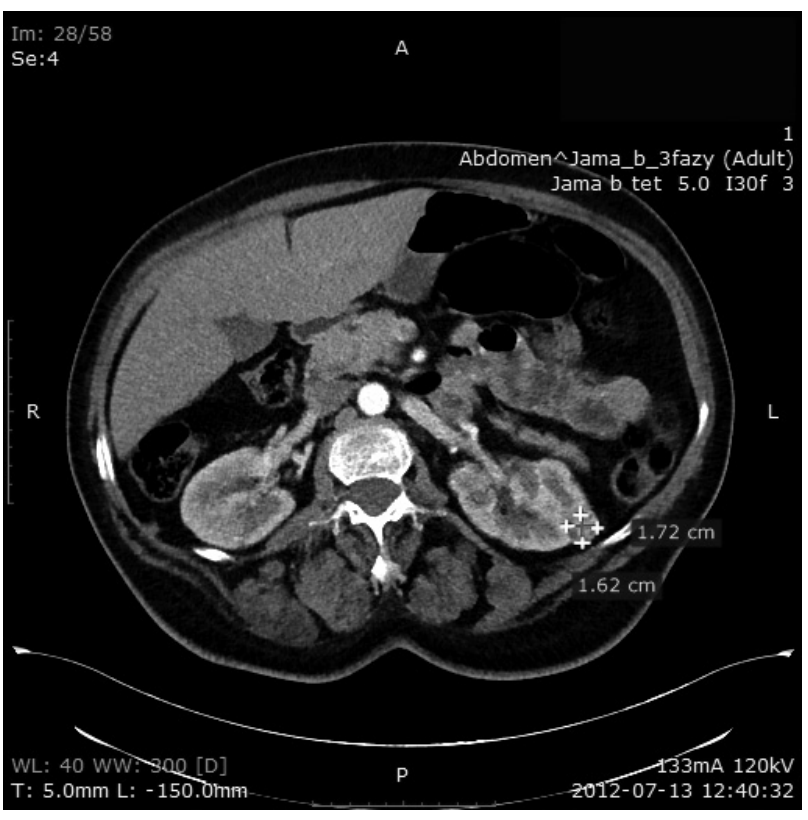

Figure 4. Left kidney tumour $(1.72 \times 1.62 \times 2.0 \mathrm{~cm})$

a microadenoma. Revision of first MRI could actually identify this lesion. The patient declined pituitary surgery; she was well-controlled with somatostatin analogue (morning random GH: $0.99 \mathrm{ng} / \mathrm{mL}$, IGF-I: $207 \mathrm{ng} / \mathrm{mL}$ ). She had a screening, which was normal. On a second chest CT one year after the acromegaly diagnosis, progression of right lung tumour was noted from $2.3 \times 2.3 \times 2.21 \mathrm{~cm}$ to $3.1 \times 2.5 \times 2.7$ with irregular borders, non-homogenous density, communicating with the pleura, with enlarged lymphatic nodes up to $1.6 \times 1.1 \mathrm{~cm}$ located in the mediastinum. Right upper lung lobe resection and mediastinal lymphadenectomy were performed showing pulmonary adenocarcinoma with normal lymph nodes (Tab. I). The patient was a non-smoker. Bone scintigraphy showed no evidence of metastases. An abdominal CT 19 months after the acromegaly diagnosis revealed a $1.7 \times 1.6 \times 2.0 \mathrm{~cm}$ left kidney tumour (Fig. 4); revision of first abdominal CT suggested no significant progression between these two scans. The patient refused kidney surgery, but a scan a year later showed progression $(2.3 \times 2.1 \times 2.5$ $\mathrm{cm})$, and nephrectomy identified a clear cell carcinoma (Tab. I). At the same time, nephrotic syndrome was diagnosed based on the clinical picture (ankle oedema), proteinuria and low total protein, low albumin and high cholesterol levels. Two years later she was again hospitalised due to increasing oedema and deterioration of renal parameters. Multiple myeloma with secondary renal amyloidosis was diagnosed. The diagnosis was confirmed by histopathological examination of the removed kidney, bone marrow aspirate, and serum analysis (positive immunofixation of plasma protein, abnormal kappa/lambda ratio). The patient underwent 
chemotherapy with bortezomib and dexamethasone. Due to a significant deterioration of the clinical condition and results of laboratory tests, which indicated a severe nephrotic syndrome, haemodialysis was initiated and chemotherapy was changed to second-line therapy with melphalan and prednisone. Currently she is feeling very well. The chemotherapy and haemodialysis are being continued with good tolerance.

Due to the various elements of her diagnosis, she underwent genetic testing. She was negative for a paraganglioma gene panel (SDHA, SDHB, SDHC, SDHD, SDHAF2, RET, VHL, MAX, and TMEM127) as well as for $A I P, M E N 1$, and CDKN1B mutations. Neurofibromatosis was ruled out based on clinical findings (lack of typical skin lesions, which have usually $100 \%$ penetrance in patients with NF1 mutations). Next-generation cancer panel containing 94 cancer genes (Illumina TruSight Cancer panel), following the workflow used previously assessing 68 genes [5], was applied to identify germline mutation explaining the multiple tumours in this patient. This did not reveal any variants classed as pathogenic.

\section{Discussion}

The patient had multiple tumours, but her disease does not fulfil any of the known tumour syndrome criteria. It has been suggested that patients with acromegaly may have an increased risk of developing malignant tumours, especially colorectal cancer, but also breast, thyroid, prostate, and hematopoietic cancers [6-11]. Orme et al. showed that increased mortality rates from colon cancer and malignant disease were associated with higher post-treatment GH level [12]. Baris et al. showed that the incidence of renal cancer was three times greater in acromegalic patients [13]. The increased risk for developing malignant tumours of the urinary system was also confirmed by Kaupinnen-Makelin et al., but only within the period of five years from the diagnosis of acromegaly [14]. Regarding haematological malignancies such as lymphoma, multiple myeloma, and leukaemia, only case reports describe association with acromegaly $[15,16]$. On the other hand, a lower odds ratio of developing neoplasms was suggested by a review [9]. Some of the studies, based on retrospective multicentre cohort studies, did not demonstrate a higher cancer incidence $[17,18]$, but these older data could be confounded by the fact that patients had premature deaths due to cardiovascular disease [19].

Our patient presented with acromegaly associated with GIST, clear cell renal cell carcinoma, lung adenocarcinoma, adrenal adenoma, thyroid follicular adenoma, medulla oblongata tumour, and multiple myeloma.
She was tested for a paraganglioma panel due to her GIST and acromegaly because $S D H$ genes can cause both GIST and pituitary adenomas [20-23], and because $V H L$ can be associated with renal cell carcinoma and CNS lesions [24] and rarely with pituitary adenoma $[25,26]$. She was tested for AIP and MEN1, although her presentation was not suggestive for either of these genes (i.e. she did not have young-onset acromegaly, she had a microadenoma easily controlled with medical therapy, and she did not present with calcium abnormalities).

GISTs can be a part of Carney triad [27], a disease characterised by the coexistence of three types of neoplasms, especially in young women: GIST, pulmonary chondroma, and extra-adrenal paraganglioma, although in most cases the triad is incomplete [28]. There is an increased incidence, however, of pheochromocytoma, oesophageal leiomyoma, and adrenocortical adenoma. The gastric lesion is usually the presenting tumour $(75 \%)$, followed by the lung lesion $(15 \%)$ and the paraganglioma (10\%). Twenty per cent of the patients have non-functioning adrenocortical adenomas, but non-functioning pheochromocytoma has also been described [29]. Rarer manifestations include and oesophageal leiomyomas, breast cancer, renal cell carcinoma, renal angiomyolipoma, colonic adenocarcinoma, thyroid adenomas, branchial cleft cysts, and parathyroid adenoma [28, 29]. Carney triad occurs as sporadic disease; no familial cases have been described. The underlying genetic defect remains unknown [27, 30, 31]. Our patient had four manifestations compatible with Carney triad: GIST, co-existing with adrenocortical adenoma, thyroid tumour, and renal cell carcinoma. GIST with paraganglioma may occur in Carney-Stratakis syndrome, which is caused by germline mutations in succinate dehydrogenase subunits $S D H D, S D H C, S D H B$ [32]. All of them were excluded in our patient.

MEN4 (multiple endocrine neoplasia 4) is characterised by the occurrence of parathyroid and anterior pituitary tumours in association with tumours of kidney, adrenals, and reproductive organs due to heterozygous mutations of cyclin-dependent kinase inhibitor p27 (CDKN1B) [33]. Our patient did not present dysfunction of the parathyroid gland, but we observed a pituitary tumour that coexisted with adrenal, kidney, and thyroid tumour. We therefore tested the patient for this mutation; however, it was not detected.

Acromegaly was also recognised in patients with neurofibromatosis 1 (NF1) [34], a genetic disorder characterised by typical skin lesions (multiple cafe au lait spots, neurofibromas, axillary and groin freckling), peripheral and central nervous system abnormalities (neurofibromas, gliomas, cognitive impairment), and 
pheochromocytomas, while GIST can be recognised in about $1 \%$ patients of NF1 $[32,35]$. Our patient does not meet the clinical criteria of NF1.

The association of acromegaly with multiple myeloma has only been described in a few case reports [15, $36,37]$. GH and IGF-I can activate B cell lymphocytes, and IGF-I receptor is expressed in multiple myeloma cells [38]. It has been suggested that IGF-I can act as an autocrine factor promoting growth and survival in multiple myeloma cell lines [39]. It was suggested that maintaining low levels of GH and IGF-I may be important in treating coexistent multiple myeloma [37]. The coexistence of multiple myeloma with other tumour types has been reported; out of 589 patients with multiple myeloma 59 patients had coexisting primary neoplasms such as colorectal (seven cases), gynaecological (seven cases), skin (six cases), urothelial (six cases), and prostate (four cases) cancer [40]. Another study indicated bidirectional association between renal cell carcinoma and multiple myeloma. These analyses revealed higher relative risk for renal cell carcinoma in patients with multiple myeloma as well as higher risk for multiple myeloma in patients with renal cell carcinoma, compared to the general population. They suggest shared risk factors for both of malignancies [41]. Only one case of co-existence of GIST and multiple myeloma has been reported [42] to date. In patients with acromegaly the occurrence of malignant kidney tumours is more frequent compared to the general population [13]. Hereditary kidney cancer syndrome accounts for about five per cent of all kidney cancers, and more than 10 syndromes have been described [43]. Von Hippel-Lindau disease (VHL) could be considered in her case due to the kidney cancer and the medulla oblongata tumour. VHL mutations were not detected.

In summary, our patient has an unusual combination of acromegaly and seven other tumour types, raising the possibility of a tumour syndrome. She does not fit any of the known tumour syndromes. Next-generation whole exome or whole genome sequencing using germline and tumour sample DNA might further help the identification of a tumour-predisposing genetic alteration. We wonder whether the elevated IGF-I had a permissive role in the growth of some of her tumours.

\section{Conflict of interest}

The authors declare that they have no conflict of interest.

\section{Informed consent}

Informed consent was obtained from this patient

\section{References}

1. Melmed S, Casanueva F, Cavagnini F, et al. Consensus statement: medical management of acromegaly. Eur J Endocrinol. 2005; 153(6): 737-740, doi: 10.1530/eje.1.02036, indexed in Pubmed: 16322377.

2. Beuschlein F, Strasburger CJ, Siegerstetter V, et al. Acromegaly caused by secretion of growth hormone by a non-Hodgkin's lymphoma. N Engl J Med. 2000; 342(25): 1871-1876, doi: 10.1056/NEJM200006223422504, indexed in Pubmed: 10861322

3. Melmed S, Ziel FH, Braunstein GD, et al. Medical management of acromegaly due to ectopic production of growth hormone-releasing hormone by a carcinoid tumor. J Clin Endocrinol Metab. 1988; 67(2): 395-399, doi: 10.1210/jcem-67-2-395, indexed in Pubmed: 2899089.

4. Arita K, Kurisu K, Tominaga A, et al. Mortality in 154 surgically treated patients with acromegaly - a 10-year follow-up survey. Endocr J. 2003; 50(2): 163-172, indexed in Pubmed: 12803236.

5. Whitworth J, Smith PS, Martin JE, et al. NIHR BioResource Rare Diseases Consortium. Comprehensive Cancer-Predisposition Gene Testing in an Adult Multiple Primary Tumor Series Shows a Broad Range of Deleterious Variants and Atypical Tumor Phenotypes. Am J Hum Genet. 2018; 103(1): 3-18, doi: 10.1016/j.ajhg.2018.04.013, indexed in Pubmed: 29909963.

6. Boikos SA, Stratakis CA. The genetic landscape of gastrointestinal stromal tumor lacking KIT and PDGFRA mutations. Endocrine. 2014; 47(2): 401-408, doi: 10.1007/s12020-014-0346-3, indexed in Pubmed: 25027296.

7. Popovic V, Damjanovic S, Micic D, et al. Increased incidence of neoplasia in patients with pituitary adenomas. The Pituitary Study Group. Clin Endocrinol (Oxf). 1998; 49(4): 441-445, indexed in Pubmed: 9876340.

8. Kurimoto M, Fukuda I, Hizuka N, et al. The prevalence of benign and malignant tumors in patients with acromegaly at a single institute. Endocr J. 2008; 55(1): 67-71, indexed in Pubmed: 18202526.

9. Loeper S, Ezzat S. Acromegaly: re-thinking the cancer risk. Rev Endoc Metab Disord. 2008; 9(1): 41-58, doi: 10.1007/s11154-007-9063-z, indexed in Pubmed: 18157698

10. Woliński K, Stangierski A, Gurgul E, et al. Thyroid lesions in patients with acromegaly - case-control study and update to the meta-analysis. Endokrynol Pol. 2017; 68(1): 2-6, doi: 10.5603/EP.2017.0001, indexed in Pubmed: 28255974.

11. Ortansa MR, Rodica A, Dumitrache M, et al. Small cell neuroendocrine thyroid carcinoma. Ther Pharmacol Clin Toxicol. 2014; 18: 171-173.

12. Orme SM, McNally RJ, Cartwright RA, et al. Mortality and cancer incidence in acromegaly: a retrospective cohort study. United Kingdom Acromegaly Study Group. J Clin Endocrinol Metab. 1998; 83(8): 2730-2734, doi: 10.1210/jcem.83.8.5007, indexed in Pubmed: 9709939.

13. Baris D, Gridley G, Ron E, et al. Acromegaly and cancer risk: a cohort study in Sweden and Denmark. Cancer Causes Control. 2002; 13(5): 395-400, indexed in Pubmed: 12146843

14. Kauppinen-Mäkelin R, Sane T, Välimäki MJ, et al. Finnish Acromegaly Study Group. Increased cancer incidence in acromegaly - a nationwide survey. Clin Endocrinol (Oxf). 2010; 72(2): 278-279, doi: 10.1111/j.1365-2 265.2009.03619.x, indexed in Pubmed: 19453622

15. Barbosa FR, Vieira Neto L, Lima GA, et al. Hematologic neoplasias and acromegaly. Pituitary. 2011; 14(4): 377-381, doi: 10.1007/s11102-009-0176-0, indexed in Pubmed: 19337840

16. Ge NL, Rudikoff S. Insulin-like growth factor I is a dual effector of multiple myeloma cell growth. Blood. 2000; 96(8): 2856-2861, indexed in Pubmed: 11023522

17. Petroff D, Tönjes A, Grussendorf M, et al. The Incidence of Cance Among Acromegaly Patients: Results From the German Acromegaly Registry. J Clin Endocrinol Metab. 2015; 100(10): 3894-3902, doi: 10.1210/jc.2015-2372, indexed in Pubmed: 26244491.

18. Orme SM, McNally RJ, Cartwright RA, et al. Mortality and cancer incidence in acromegaly: a retrospective cohort study. United Kingdom Acromegaly Study Group. J Clin Endocrinol Metab. 1998; 83(8) 2730-2734, doi: 10.1210/jcem.83.8.5007, indexed in Pubmed: 9709939.

19. Mustacchi P, Shimkin MB. Occurrence of cancer in acromegaly and in hypopituitarism. Cancer. 1957; 10(1): 100-104, indexed in Pubmed: 13413804

20. Miettinen M, Lasota J. Succinate dehydrogenase deficient gastrointestinal stromal tumors (GISTs) - a review. Int J Biochem Cell Biol. 2014; 53 : 514-519, doi: 10.1016/j.biocel.2014.05.033, indexed in Pubmed: 24886695

21. Aflorei ED, Korbonits M, Garcia EA, et al. Characterization of SNARE proteins in human pituitary adenomas: targeted secretion inhibitors as a new strategy for the treatment of acromegaly? J Clin Endocrinol Metab. 2013; 98(12): E1918-E1926, doi: 10.1210/jc.2013-2602, indexed in Pubmed: 24152687.

22. Burgoyne AM, Somaiah N, Sicklick JK. Gastrointestinal stromal tumors in the setting of multiple tumor syndromes. Curr Opin Oncol. 2014; 26(4): 408-414, doi: 10.1097/CCO.0000000000000089, indexed in Pubmed: 24840526.

23. Dénes J, Swords F, Rattenberry E, et al. Heterogeneous genetic background of the association of pheochromocytoma/paraganglioma and 
pituitary adenoma: results from a large patient cohort. J Clin Endocrinol Metab. 2015; 100(3): E531-E541, doi: 10.1210/jc.2014-3399, indexed in Pubmed: 25494863.

24. Maher ER, Neumann HPh, Richard S. von Hippel-Lindau disease: a clinical and scientific review. Eur J Hum Genet. 2011; 19(6): 617-623, doi: 10.1038/ejhg.2010.175, indexed in Pubmed: 21386872.

25. Tudorancea A, François P, Trouillas J, et al. Von Hippel-Lindau disease and aggressive GH-PRL pituitary adenoma in a young boy. Ann Endocrinol (Paris). 2012; 73(1): 37-42, doi: 10.1016/j.ando.2011.12.001, indexed in Pubmed: 22265326.

26. Shimoda Y, Ogawa Y, Endo H, et al. Coexistence of sporadic cerebellar hemangioblastoma and pituitary null cell adenoma: simultaneous expression of von Hippel-Lindau gene product. Case report. Neurol Med Chir (Tokyo). 2012; 52(8): 591-594, indexed in Pubmed: 22976143.

27. Diment J, Tamborini E, Casali P, et al. Carney triad: case report and molecular analysis of gastric tumor. Hum Pathol. 2005; 36(1): 112-116, doi: 10.1016/j.humpath.2004.10.003, indexed in Pubmed: 15712189.

28. Sawhney SA, Chapman AD, Carney JA, et al. Incomplete Carney triad - a review of two cases. QJM. 2009; 102(9): 649-653, doi: 10.1093/qjmed/hcp078, indexed in Pubmed: 19561114.

29. Carney JA. Carney triad: a syndrome featuring paraganglionic, adrenocortical, and possibly other endocrine tumors. J Clin Endocrinol Metab. 2009; 94(10): 3656-3662, doi: 10.1210/jc.2009-1156, indexed in Pubmed: 19723753.

30. Boikos SA, Xekouki P, Fumagalli E, et al. Carney triad can be (rarely) associated with germline succinate dehydrogenase defects. Eur J Hum Genet. 2016; 24(4): 569-573, doi: 10.1038/ejhg.2015.142, indexed in Pubmed: 26173966.

31. Carney JA, Stratakis CA, Young WF. Adrenal cortical adenoma: the fourth component of the Carney triad and an association with subclinical Cushing syndrome. Am J Surg Pathol. 2013; 37(8): 1140-1149, doi: 10.1097/PAS.0b013e318285f6a2, indexed in Pubmed: 23681078.

32. Boguszewski CL, Fighera TM, Bornschein A, et al. Genetic studies in a coexistence of acromegaly, pheochromocytoma, gastrointestinal stromal tumor (GIST) and thyroid follicular adenoma. Arq Bras Endocrinol Metabol. 2012; 56(8): 507-512, indexed in Pubmed: 23295290.
33. Thakker RV. Multiple endocrine neoplasia type 1 (MEN1) and type 4 (MEN4). Mol Cell Endocrinol. 2014; 386(1-2): 2-15, doi: 10.1016/j. mce.2013.08.002, indexed in Pubmed: 23933118.

34. Gadelha MR, Kasuki L, Korbonits M. The genetic background of acromegaly. Pituitary. 2017; 20(1): 10-21, doi: 10.1007/s11102-017-0789-7, indexed in Pubmed: 28161730.

35. Garrido AC, Picó Cd. Acromegalia y neurofibromatosis tipo 1. ¿Es casual la asociación entre ambas entidades? Endocrinología y Nutrición. 2013; 60(3): 144-145, doi: 10.1016/j.endonu.2012.01.020.

36. Hägg E, Asplund K, Holm J. Acromegaly and multiple myeloma. Ann Intern Med. 1988; 109(5): 437-438, indexed in Pubmed: 3408064.

37. Kang YuMi, Choi JH, Lee MJ, et al. Multiple myeloma in a patient with acromegaly. Endocrinol Metab (Seoul). 2015; 30(1): 110-115 doi: 10.3803/EnM.2015.30.1.110, indexed in Pubmed: 25491781.

38. Åman P, Lundin G, Hall K, et al. Insulin receptors on human lymphoid lines of B-cell origin. Cell Immunol. 1981; 65(2): 307-316, doi: 10.1016/ 0008-8749(81)90076-9.

39. Georgii-Hemming P, Strömberg T, Janson ET, et al. Insulin-like growth factor $I$ is a growth and survival factor in human multiple myeloma cell lines. Blood. 1996; 88(6): 2250-2258, indexed in Pubmed: 8822946.

40. Hasskarl J, Ihorst G, De Pasquale D, et al. Association of multiple myeloma with different neoplasms: systematic analysis in consecutive patients with myeloma. Leuk Lymphoma. 2011; 52(2): 247-259, doi: 10. 3109/10428194.2010.529207, indexed in Pubmed: 21054148.

41. Ojha RP, Evans EL, Felini MJ, et al. The association between renal cell carcinoma and multiple myeloma: insights from population-based data. BJU Int. 2011; 108(6): 825-830, doi: 10.1111/j.1464-410X.2010.09892 $x$, indexed in Pubmed: 21091979.

42. Tzilves D, Gatopoulou A, Zervas K, et al. Development of multiple myeloma in a patient with gastrointestinal stromal tumor treated with imatinib mesylate: a case report. World J Gastroenterol. 2007; 13(13): 2011-2013, indexed in Pubmed: 17461509.

43. Hasumi H, Yao M. Hereditary kidney cancer syndromes: Genetic disorders driven by alterations in metabolism and epigenome regulation. Cancer Sci. 2018; 109(3): 581-586, doi: 10.1111/cas.13503, indexed in Pubmed: 29325224. 